SILKOFF et al. [7] hypothesised that increased Daw,NO might be an early manifestation of asthma. However, we found no evidence to support this, since the distribution of Daw,NO was similar for both groups. In contrast, the range of $\mathrm{Caw}$,NO values in the wheezers appeared to be higher than in controls. In asthmatics, Daw,NO is elevated compared with controls $[7,8]$ but $\mathrm{Caw}, \mathrm{NO}$ is not [7]. Factors determining Caw,NO and Daw,NO may be different in infants with early asthma symptoms compared with older individuals who have established disease.

Among the control subjects in the present study, values of Daw,NO in controls were higher than reported previously (range 3-37 $\mathrm{nL} \cdot \mathrm{s}^{-1} \cdot \mathrm{ppb}$ [4]) and CawNO values were lower (49$385 \mathrm{ppb}$ [4]). Apparent differences in FIP values between studies are most likely explained by the small numbers of participants in both studies. In addition, the FeNO values at low flows, known to predominantly influence Daw,NO and Caw,NO [1] differed between studies. The majority of mothers of control infants in the present study were atopic and this is relavent since maternal atopy is known to influence nitric oxide in infants [9].

In summary, we report values of flow independent nitric oxide parameters in infants with and without wheeze. These unique data may be of interest to colleagues interested in nitric oxide physiology in healthy and wheezy infants.

\section{S.W. Turner*, P.J. Franklin*, R.C. Mutch* and S.M. Stick*\# *School of Paediatrics and Child Health, University of Western Australia, and "Dept of Respiratory Medicine, Princess Margaret Hospital for Children, Perth, Australia.}

\section{STATEMENT OF INTEREST}

None declared.

\section{REFERENCES}

1 George SC, Hogman M, Permutt S, Silkoff PE. Modeling pulmonary nitric oxide exchange. J Appl Physiol 2004; 96: 831-839.

2 Latzin P, Kuehni CE, Baldwin DN, Roiha HL, Casaulta C, Frey U. Elevated exhaled nitric oxide in newborns of atopic mothers precedes respiratory symptoms. Am J Respir Crit Care Med 2006; 174: 1292-1298.

3 Franklin PJ, Turner S, Mutch R, Stick SM. Parental smoking increases exhaled nitric oxide in young children. Eur Respir J 2006; 28: 730-733.

4 Martinez T, Weist A, Williams T, Clem C, Silkoff P, Tepper RS. Assessment of exhaled nitric oxide kinetics in healthy infants. J Appl Physiol 2003; 94: 2384-2390.

5 Franklin PJ, Turner SW, Mutch R, Stick SM. Comparisons of single breath and tidal breathing exhaled nitric oxide levels in infants. Eur Respir J 2004; 23: 369-372.

6 Wildhaber JH, Hall GL, Stick SM. Measurements of exhaled nitric oxide with the single-breath technique and positive expiratory pressure in infants. Am J Respir Crit Care Med 1999; 159: 74-78.

7 Silkoff PE, Sylvester JT, Zamel N, Permutt S. Airway nitric oxide diffusion in asthma: Role in pulmonary function and bronchial responsiveness. Am J Respir Crit Care Med 2000; 161: 1218-1228.

8 Pedroletti C, Hogman M, Merilainen P, Nordvall LS, Hedlin G, Alving K. Nitric oxide airway diffusing capacity and mucosal concentration in asthmatic schoolchildren. Pediatr Res 2003; 54: 496-501.

9 Frey U, Kuehni C, Roiha $\mathrm{H}$, et al. Maternal atopic disease modifies effects of prenatal risk factors on exhaled nitric oxide in infants. Am J Respir Crit Care Med 2004; 170: 260-265.

\title{
Vitamins as asthmagens in the workplace
}

\section{To the Editors:}

The cross-sectional study by SRIPAIBOONKIJ et al [1] on 167 milk powder factory workers from four factories in Thailand reported an increased risk of developing work related symptoms compared with office workers. Milk protein allergy as a cause of occupational asthma is well recognised. In addition, many of the studied workers were exposed to the vitamin mixtures used to fortify milk powder. Workers exposed to vitamins had poorer lung function, with significant reductions in forced vital capacity, and an increased risk of nasal, skin and eye symptoms. Breathlessness and nasal symptoms were increased in packing workers, who were also exposed to vitamins in their work. SRIPAIBOONKIJ et al [1] suggest that the skin symptoms were probably related to natural rubber latex from the factory workers' gloves.

Vitamins are chemically unrelated organic compounds that the body cannot synthesise in sufficient quantities on its own (with the exception of vitamin D), but are essential in small amounts to maintain a normal metabolism and good health. DROUGHT et al. [2] have previously reported occupational asthma caused by thiamine (vitamin $\mathrm{B}_{1}$ ) in workers in a cereal factory, confirmed with specific bronchial provocation tests. Using the quantitative structure-activity relationship (QSAR) model linking chemical structure and their occupational asthma hazard [3], the thiamine molecule has been shown to have a high risk of being a chemical respiratory sensitiser with a hazard index of 0.95 [4].

We used the chemical asthma hazard assessment programme based on the above model to study the common vitamin compounds. The asthma hazard index of a chemical is expressed as a value $0-1$, with 1 indicating definite asthmagenic potential.

Table 1 shows that vitamins $A, D, B_{1}, B_{2}, B_{3}, B_{5}$, biotin and folic acid molecules carry a high probability of causing respiratory sensitisation. Folic acid, which is one of the commonest fortifying agents, has the greatest hazard index of 1 . When the vitamins tested are in the salt form (e.g. pyridoxine hydrochloride), the 


\begin{tabular}{|c|c|c|}
\hline Vitamin & Molecular mass Da & Hazard index \\
\hline All-trans retinoic acid (A) & 300.44 & 0.9329 \\
\hline Retinyl palmitate (A) & 524.88 & 0.9974 \\
\hline beta-carotene (provitamin A) & 536.89 & 0.9970 \\
\hline Ergocalciferol $\left(D_{2}\right)$ & 396.66 & 0.9432 \\
\hline Cholecalciferol $\left(D_{3}\right)$ & 384.65 & 0.9355 \\
\hline Tocopherol acetate (E) & 472.76 & 0.9036 \\
\hline Naphthoquinone (K) & 158.16 & 0.1600 \\
\hline Phylloquinone $\left(\mathrm{K}_{1}\right)$ & 116.16 & 0.1157 \\
\hline Menaquinone $\left(\mathrm{K}_{2}\right)$ & 168.15 & 0.2958 \\
\hline Menadione (Provitamin K) & 172.19 & 0.2044 \\
\hline Thiamine $\left(B_{1}\right)$ & 263.34 & 0.9400 \\
\hline Thiamine hydrochloride $\left(B_{1}\right)$ & 338.28 & 0.9469 \\
\hline Thiamine mononitrate $\left(B_{1}\right)$ & 329.38 & 0.9548 \\
\hline Riboflavin $\left(B_{2}\right)$ & 376.37 & 0.9987 \\
\hline Niacin $\left(B_{3}\right)$ & 123.11 & 0.9169 \\
\hline Pantothenic acid $\left(B_{5}\right)$ & 219.24 & 0.9896 \\
\hline Pyridoxine $\left(B_{6}\right)$ & 169.18 & 0.0963 \\
\hline Pyridoxine hydrochloride $\left(B_{6}\right)$ & 205.64 & 0.0948 \\
\hline Biotin $\left(\mathbf{H} / \mathbf{B}_{7}\right)$ & 244.31 & 0.9631 \\
\hline Folic acid $\left(B_{9}\right)$ & 441.41 & 1.0000 \\
\hline Cyanocobalamin $\left(B_{12}\right)^{\#}$ & 1355.37 & \\
\hline Ascorbic acid (C) & 176.13 & 0.0196 \\
\hline
\end{tabular}

spectator anion seems to alter the hazard index only marginally. Significant differences in asthmagenicity are not observed between the provitamin, the naturally occurring vitamin or its synthetic derivative used in industry. The positive predictive value of the QSAR for the identification of suspect chemical asthmagens is $>50 \%$. Even in the context of testing random chemicals for asthmagens, the QSAR has a negative predictive value of $100 \%$; thus vitamins $B_{6}, C$ and $K$ are certainly nonasthmagens. The property of water or fat solubility, which forms the basis of the traditional classification of vitamins, does not seem to be a determinant of a vitamin's asthma hazard index. Skin sensitisers are typically more hydrophobic than respiratory sensitisers. Both water-soluble and fat-soluble vitamins are used as additives in the food industry. Exposure at work to both of the above classes of vitamin compounds may occur, resulting in respiratory and skin sensitisation of workers during the manufacturing process.

In the milk powder factory study, it is possible that many of the work-related symptoms were caused by exposure to the vitamin compounds added to the milk powder [1]. Vitamins are commonly used as fortifying agents in the food industry and their asthmagenic potential in the workplace needs to be recognised.

\section{A.D. Vellore, S. Madathil, R.A. Heinink, V.C. Moore, S. Manney, C. Burge and P.S. Burge}

Occupational Lung Disease Unit, Birmingham Heartlands Hospital, Birmingham, UK.

\section{STATEMENT OF INTEREST}

None declared.

\section{REFERENCES}

1 Sripaiboonkij P, Phanprasit W, Jaakkola MS. Respiratory effects of occupational exposures in a milk powder factory. Eur Respir J 2008; 31: 807-814.

2 Drought VJ, Francis HC, Niven RMcL, Burge PS., Occupational asthma induced by thiamine in a vitamin supplement for breakfast cereals. Allergy 2005; 60: 1213-1214.

3 Jarvis J, Seed MJ, Elton R, Sawyer L, Agius R. Relationship between chemical structure and the occupational asthma hazard of low molecular weight organic compounds. Occup Environ Med 2005; 62: 243-250.

4 Seed MJ, Agius RM. Prediction of asthma hazard of thiamine. Allergy 2006; 61: 648.

DOI: $10.1183 / 09031936.00065108$

\section{From the authors:}

We recently reported results of a cross-sectional study of 167 milk powder factory workers and 76 office workers from Thailand showing that production and packing workers exposed to relatively low concentrations of milk powder experienced significantly increased risk of nasal symptoms and breathlessness, had clearly increased risk of wheezing and asthma, and had reduced spirometry [1]. Workers who added a vitamin mixture to milk had significantly increased risk of skin symptoms, in addition to having increased risk of nasal symptoms and reduced lung function. A.D. Vellore and colleagues address the respiratory sensitisation potential of vitamins by applying a quantitative structure-activity relationship model developed by JARvis et al. [2] for low molecular weight agents. Based on an asthma hazard index calculated by the model, they conclude that vitamins, apart from vitamins B6, C and $\mathrm{K}$, have high potential asthmagenicity. A.D. Vellore and colleagues suggest that in our milk powder factory study, exposure to vitamin compounds might explain "many of the work-related symptoms". The latter conclusion seems to be based on the chemical structure of vitamins, one previous case report of occupational asthma related to exposure to thiamine in a cereal worker, and some misunderstandings concerning our study, which need to be corrected.

In our study of the milk powder factory, only 22 (13\%) of 167 factory workers worked in the vitamin-adding area, where they had exposure to a mixture of vitamins, minerals and corn syrup [1]. All vitamin-adding workers also had exposure to milk powder, while the other 145 workers did not have significant exposure to the vitamin mixture. Thus, it is not possible that exposure to vitamins could explain a high proportion of the respiratory symptoms detected in our study. When looking at individual exposures in the factory, milk powder was most consistently related to respiratory symptoms and reduced lung function. What was unique to vitaminadding staff was increased risk of skin symptoms, which was most likely related to their use of natural rubber latex gloves, although it cannot be excluded that some of the skin symptoms could be explained by vitamin exposure. 